\title{
EPIDEMIOLOGICAL AND ORAL MANIFESTATIONS OF HIV-POSITIVE PATIENTS IN A SPECIALIZED SERVICE IN BRAZIL
}

\author{
Erick Nelo PEDREIRA', Camila Lopes CARDOSO², Éder do Carmo BARROSO³, Jorge André de Souza SANTOS, \\ Felipe Paiva FONSECA ${ }^{4}$, Luís Antônio de Assis TAVEIRA ${ }^{5}$
}

\begin{abstract}
1- DDS, MSc, PhD, Assistant Professor of Pathological Sciences, Department of Stomatology, Dental School, Federal University of Pará, Belém, PA. 2- DDS, Graduate student, Department of Stomatology, Bauru School of Dentistry, University of São Paulo, Bauru, SP, Brazil.

3- DDS, Ex-trainee of the Discipline of Pathological Sciences, Department of Stomatology, Dental School, Federal University of Pará, Belém, PA.

4- Undergraduated student, Dental School, Federal University of Pará, Belém, PA.

5- DDS, MSc, PhD, Associate Professor, Department of Stomatology, Bauru School of Dentistry, University of São Paulo, Bauru, SP, Brazil.

Corresponding address: Camila Lopes Cardoso - Faculdade de Odontologia de Bauru - FOB - USP / Departamento de Patologia - Alameda Octávio Pinheiro Brisolla, 9-75; 17012-901 Bauru, SP, Brasil - Phone: +55-14-3235-8248. Fax: +55-14-3235-8251 - e-mail: cardoso_lopes@hotmail.com and
\end{abstract} cardoso_lopes@yahoo.com.br

Received: September 6, 2007 - Modification: June 18, 2008 - Accepted: June 22, 2008

\begin{abstract}
$T_{\mathrm{h}}$

Le purpose of this study was to evaluate the prevalence of oral lesions in HIV-positive patients attending the Specialized Service for Infectious-contagious Diseases and Parasitoses of the Health Secretariat of the State of Pará (URE-DIPE/SESPA), in the city of Belém, PA, Brazil. A total of 79 HIV-positive patients (53 males and 26 females) were examined. Clinical and epidemiological evaluations were done by correlating the lesions with gender, race, chronological age, risk behavior and prevailing immune status (CD4+ cells count). Lesion location and the presence of associated factors, such as alcohol use, smoking and denture wearing, were quantified individually for each type of lesion using a diagnostic pattern based on the clinical aspects. Approximately $47 \%$ of the patients $(n=37)$ presented some type of oral lesion. Candidiasis $(28 \%)$ and periodontal disease $(28 \%)$ were the most common, followed by cervical-facial lymphadenopathy (17.5\%). Other lesions observed were hairy leukoplakia, melanin hyperpigmentation, ulcerative stomatitis (aphthous), herpes simplex, frictional keratosis and pyogenic granuloma. This analysis presented some relevance as to the statistical data. Concerning CD4+ cells, most lesions manifested with the reduction of the CD count. There were a larger number of HIV-positive female heterosexual patients. Alcohol and/or smoking were strongly associated with the occurrence of hairy leukoplakia in these patients. Candidiasis and periodontal disease were the most common oro-regional clinical manifestations in the patients.
\end{abstract}

Key words: Oral manifestations. Acquired immunodeficiency syndrome, diagnostic. Candidiasis.

\section{INTRODUCTION}

Since the appearance of the first cases of contamination by the HIV virus, in the 1980s, there has been a continuous and progressive increase in the number of infected patients. Currently, much is known about the etiology and pathogenesis of this infection, which allows increasingly accurate diagnoses in early stages of the disease.

In the field of Dentistry, the lack of knowledge regarding the systemic aspects of AIDS, and its subsequent oral manifestations leads to severe limitations and deficiencies in the treatment of HIV-positive patients. Today, it is known that AIDS corresponds to a series of signs and symptoms characterized by an association of opportunistic diseases that appear during the immune suppressive state caused by the HIV virus. Such diseases may cause several oral manifestations, which may often precede the systemic manifestations or may even be exclusive manifestations of the disease.

Oral lesions are common in patients infected by the HIV virus and may indicate an impairment in the patient's general health status and consequently a poor prognosis. Many of these HIV-positive patients present manifestations involving the maxillofacial region in all stages of the disease, and, in some cases, the oral lesions are the first signs of infection. Moreover, some authors state that oral manifestations are the earliest sign of HIV infection ${ }^{6,20}$.

Oral candidiasis is clinically classified as a white spot 
lesion that may be removed by friction of a gauze pad (pseudomembranous candidiasis). Sometimes, these white spots are followed by an erythematous component, or arranged as an erythema with diffuse plates that may be associated with surfaces under dentures (erythematous candidiasis). A characteristic similar to infection by Candida albicans may be observed at the lip commissure in patients with reduced vertical dimension, being called cheilitis, which occasionally may assume a hyperplastic aspect.

Hairy leukoplakia is another oral lesion associated with AIDS, and is considered an early sign of infection by the HIV virus ${ }^{12}$, and also as the most common lesion associated with HIV infection ${ }^{15}$. Other authors classify hairy leukoplakia as pathognomonic of HIV infection ${ }^{5}$.

Studies have associated gingivitis and periodontitis with AIDS $^{29}$. Gingivitis associated to AIDS has been described as clinically presenting an erythematous line along the free marginal gingiva, which easily bleeds, and is followed by small reddish lesions surrounding the gingiva and adjacent alveolar mucosa ${ }^{13}$.

Another clinical aspect associated to AIDS is the presence of persistent generalized lymphadenopathy, a term described by the Centers for Disease Control and Prevention (CDC), which is an agency of the United States Department of Health and Human Services ${ }^{4}$ when there are at least two or more extra-inguinal regions with the condition, for 3 or more months. Kaposi's sarcoma was described as a classical disease of AIDS, occurring in nearly $20 \%$ of patients affected by the disease ${ }^{27}$. Around 3,970 cases of Kaposi's sarcoma associated with AIDS have been recorded in the CDC until the end of 1986.

Other lesions associated with AIDS are herpes virus, which represents the viral infection with most common oral manifestation $^{18}$, melanin hyperpigmentation, ulcerative stomatitis, frictional keratosis and pyogenic granuloma ${ }^{19}$. Dentists should suspect of an early stage of HIV infection in patients with any oral lesion. However, in some cases, microscopic examination is mandatory for a definitive diagnosis. In these cases, confirmation of HIV infection may be performed by viral culture or detection of antigens or antibodies for $\mathrm{HIV}^{19}$. The most frequently employed test is the Enzyme-linked immunosorbent assay (ELISA), which determines the presence of antibodies for HIV. This test may present false-positive results and should be confirmed by a more accurate analysis of antibodies known as Western Blot, which is considered an international reference ${ }^{17}$.

Evaluation of the reduction of circulating CD4+ cell count is the main characteristic of destruction of the immune system in HIV-positive patients. Carey, et al. ${ }^{3}$ (2005) mentioned that the number of circulating CD4+ cells ranges from 600 to 1,600 cells $/ \mathrm{mm}^{3}$ of blood, and the mean count is nearly 1,000 cells $/ \mathrm{mm}^{3}$. Some studies have demonstrated that the initial signs of immune suppression occur after CD4+ cell count is lower than 500 cells $/ \mathrm{mm}^{3,8}$. The authors further mentioned that, as the number of CD4+ cells is reduced, the appearance of other lesions associated to the HIV virus increases.

The issues addressed above demonstrate the dentist's role as a health professional in the identification, diagnosis and treatment of HIV-associated lesions, providing proper guidance to the patient, and allowing for an early diagnosis of the disease, which is fundamental for a successful management of the life conditions of HIV-infected patients.

\section{MATERIAL AND METHODS}

The sample comprised 79 HIV-positive patients attending the Specialized Service for Infectious-contagious Diseases and Parasitoses (URE-DIPE) of the Health Secretariat of the State of Pará (SESPA), in the city of Belém, PA, Brazil. The project had been previously approved by the Institutional Review Board of the Dental School of the Federal University of Pará, and permission was also given by the director of URE-DIPE for carrying out clinical examinations of the patients enrolled in the study. All patients were informed about the objective of the study and signed an informed consent form before data collection in an appropriate clinical form.

Seropositivity was confirmed in all patients by the ELISA test, and classification of the lesions was based on their clinical aspects. The examiners had been previously calibrated and supervised by a dentist in the dental office during accomplishment of physical and clinical examination.

The patient files available in the service were reviewed for information related to sexual habits, use of injectable drugs, hemophilia, blood transfusion, CD4+ cell count and quantification of viral load. Information on the evolution of the disease and associated opportunistic infections was also achieved. The period of contamination was established from the date of the result of the ELISA test, a technique that has been widely used for detection of antibodies for HIV. Concerning race, the examined individuals were classified as white, admixture or black.

Intraoral clinical examination was performed in a dental chair using a dental mirror, millimeter periodontal probe, $5 \times 5 \mathrm{~cm}$ gauze pads, tongue depressors and artificial lighting.

After clinical examination and completion of the forms, the results were submitted to descriptive analysis (percentage) of the data related to the 79 HIV-positive patients assisted at the dental clinic of URE-DIPE/SESPA.

\section{RESULTS}

Planning of the study population followed a simple random sampling, which was developed independently by use of the patient attendance form. The primary objective was to describe quantitatively the lesions in their different levels and relate them to other variables, such as gender, risk behavior, aggravating factor, race, CD4+ cell count, age and location of the lesion. Thirty-seven patients (47\%) presented one or more oral alterations.

Of the 79 patients, 53 (67\%) were male and 26 (33\%) were female. Regarding risk behavior, from the 37 patients presenting at least one lesion, 11 were homosexual (all male) 


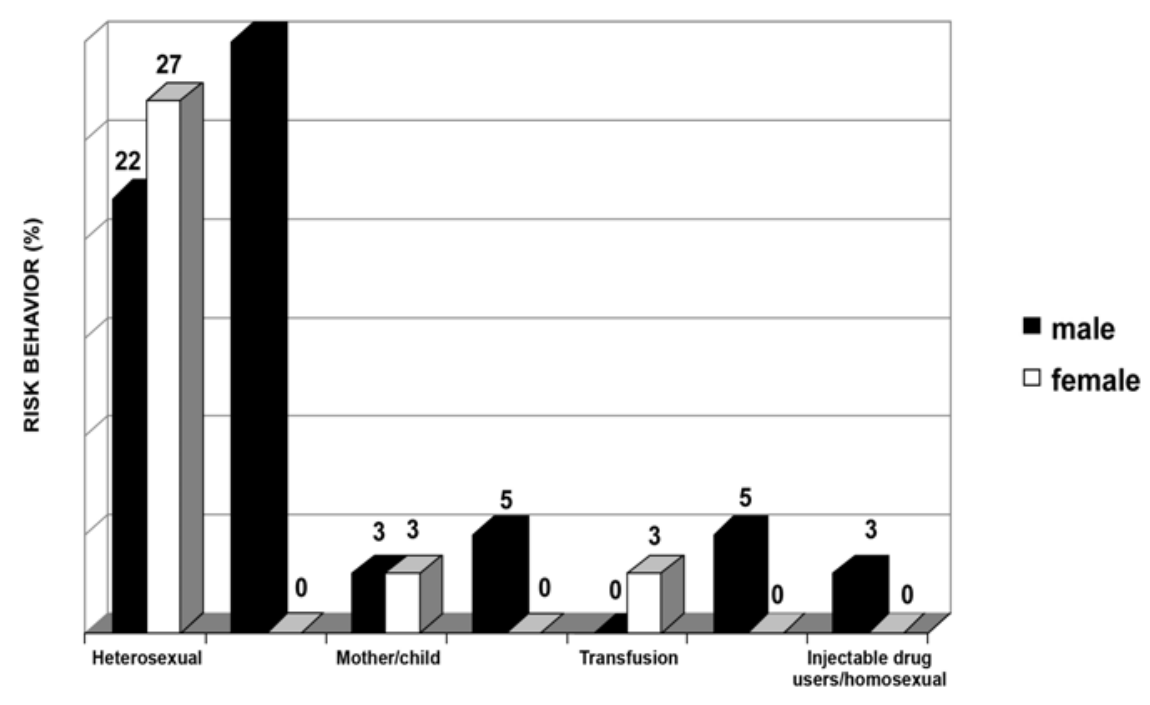

FIGURE 1- Risk behavior (\%) of patients with oral lesions

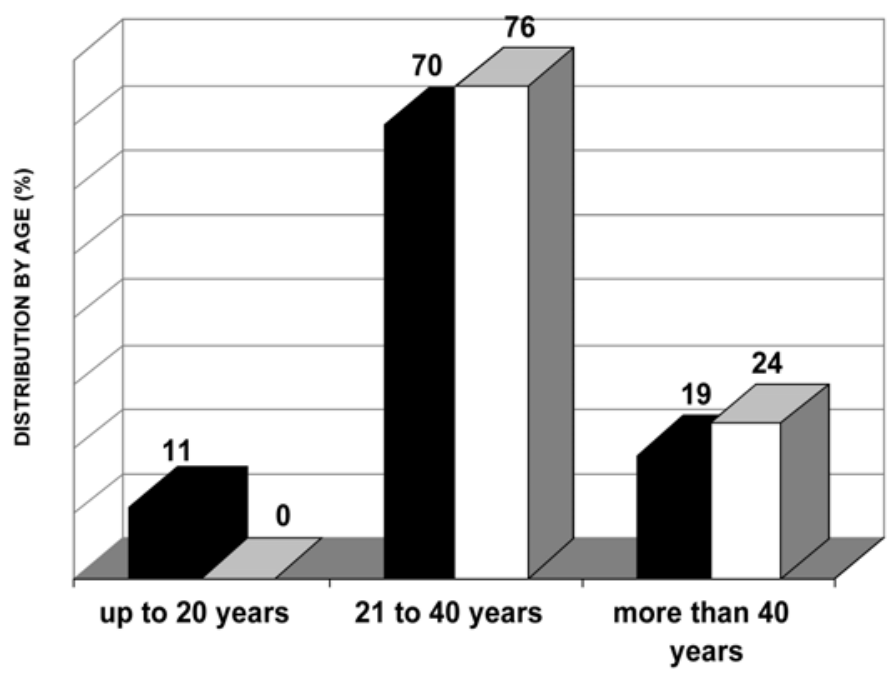

- Patients with lesion

$\square$ Patients without lesion

FIGURE 2- Distribution (\%) of patients by age

TABLE 1- Frequency of lesions

\begin{tabular}{lrr}
\hline Lesion & \multicolumn{2}{c}{ Total } \\
& $\mathrm{n}$ & $\%$ \\
\hline Candidiasis & 16 & 28 \\
Erythematous & 7 & 12 \\
Pseudomembranous & 5 & 9 \\
Cheilitis & 4 & 7 \\
Aphthous stomatitis & 2 & 4 \\
Gingivitis/periodontitis & 16 & 28 \\
Pyogenic granuloma & 1 & 2 \\
Herpes virus & 1 & 2 \\
Hyperpigmentation & 4 & 7 \\
Traumatic hyperkeratosis & 2 & 4 \\
Leukoplakia & 5 & 9 \\
Lymphadenopathy & 10 & 18 \\
TOTAL & 57 & 100 \\
\hline
\end{tabular}

TABLE 2- Location of the lesions

\begin{tabular}{lrr}
\hline Location & $\mathbf{n}$ & \% \\
\hline Tongue edges & 6 & 11 \\
Tongue dorsum & 4 & 7 \\
Palate/gingiva & 1 & 2 \\
Oral mucosa & 4 & 7 \\
Palate & 8 & 14 \\
Lips & 1 & 2 \\
Tongue border/oral mucosa & 3 & 5 \\
Oral mucosa/palate/gingiva/ & & \\
tongue dorsum & 2 & 4 \\
Palate/tongue dorsum/gingiva & 4 & 7 \\
Oral mucosa/palate/tongue dorsum & 3 & 5 \\
Palate/oral mucosa & 2 & 4 \\
Others & 19 & 33 \\
TOTAL & 57 & 100 \\
\hline
\end{tabular}


(30\%), 18 were heterosexual (10 female and 8 male) (49\%), 2 were infected by the mother (6\%), 1 was a bloodtransfusion patient (3\%), 2 were injectable drug users (5\%), 1 was injectable drug user and homosexual, and only 2 patients did not report any sort of risk behavior (5\%) (Figure 1).

It was noticed that, among the patients with lesions, 70\% were aged 21 to 40 years, being $68 \%$ males and $32 \%$ females (Figure 2). A total of 57 lesions were diagnosed in the 37 patients presenting at least one lesion. The most frequent lesions were candidiasis (28\%), gingivitis/periodontitis (28\%) and lymphadenopathy (18\%). All other lesions occurred in less than $12 \%$ of cases (Table1).

Of the 37 patients who presented with oral lesions, 57\% had only 1 lesion, 35\% presented 2 lesions and 8\% had more than 2 lesions. Most patients exhibited lesions concentrated in the palate (14\%) and lateral border of the tongue (11\%). The remaining $75 \%$ of the patients presented lesions distributed in the regions (Table 2).

Most patients with lesions (38\%) presented with 500 to 200 CD4+ cells $/ \mathrm{mm}^{3}$ of blood, whereas $16 \%$ of patients had less than $200 \mathrm{CD} 4+$ cells $/ \mathrm{mm}^{3}$ of blood. Only $5 \%$ of the patients presented more than $500 \mathrm{CD} 4+$ cells $/ \mathrm{mm}^{3}$ of blood. Counting of CD4+ cells was not available for $41 \%$ of the sample.

Lesions were more frequent for the admixture race, and less frequent among the blacks. The most representative lesions were candidiasis (21\%) and gingivitis/periodontitis (23\%) for whites; lymphadenopathy (15\%), leukoplakia (11\%), gingivitis (11\%) and candidiasis (10\%) for the admixture race; and candidiasis (22\%) for blacks (Figure 3).

Alcohol and smoking were the most frequent aggravating factors, and were related with some type of lesion in 65\% of cases. In $100 \%$ of cases, denture wearing was considered as an aggravating factor because of its close proximity to the lesion, occurring exclusively in patients with oral lesions (Figure 4).

The table 3 presents the occurrence of lesions related to CD4+ cell count.

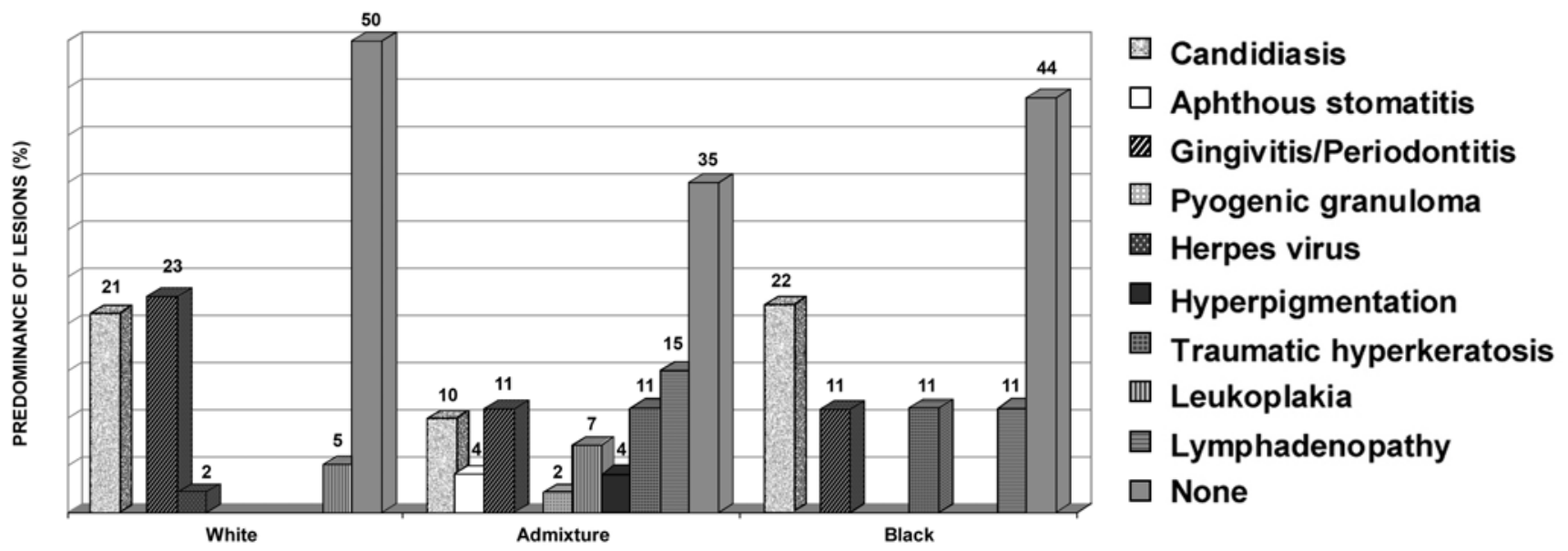

FIGURE 3- Predominance (\%) of lesions by race

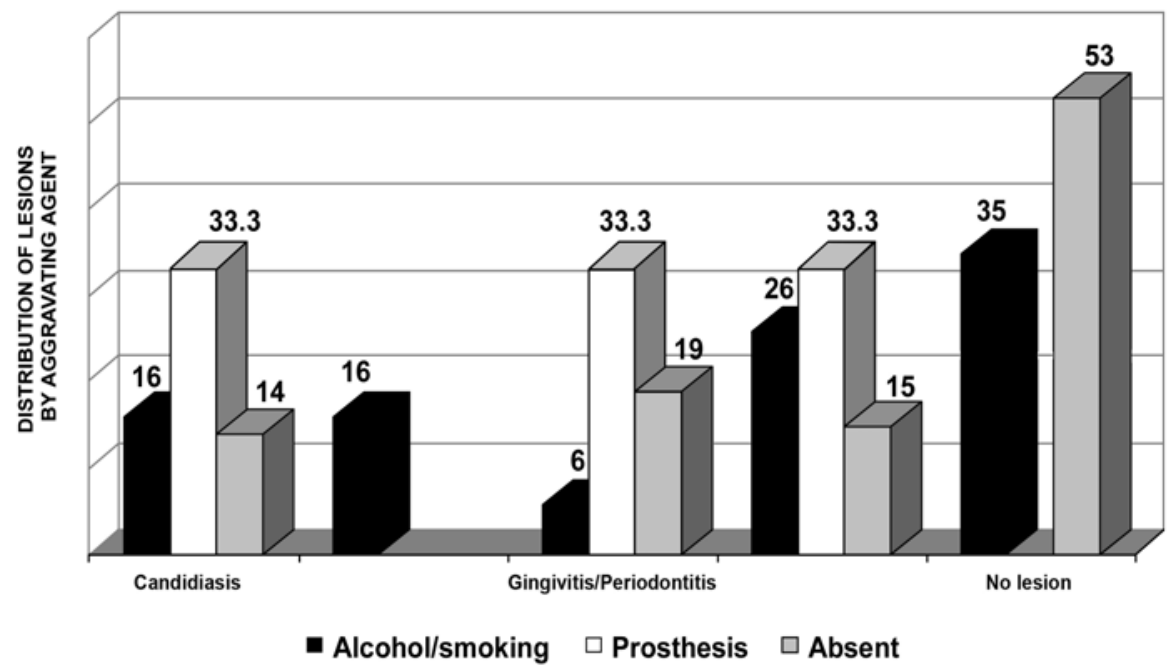

FIGURE 4- Distribution (\%) of oral lesions according to the aggravating agent 
TABLE 3- Oral lesion $\times$ CD4+ cells $/ \mathrm{mm}^{3}$ of blood

\begin{tabular}{|c|c|c|c|c|c|c|}
\hline \multirow[t]{2}{*}{ Lesion } & \multicolumn{6}{|c|}{ Counting of CD4+ cells $/ \mathrm{mm}^{3}$} \\
\hline & $>500$ & $500 / 200$ & $<200$ & Unknown & $\mathbf{n}$ & $\%$ \\
\hline Candidiasis & - & 5 & 3 & 8 & 16 & 28 \\
\hline Erythematous & - & 4 & - & 3 & 7 & 12 \\
\hline Pseudomembranous & - & - & 2 & 3 & 5 & 9 \\
\hline Cheilitis & - & 1 & 1 & 2 & 4 & 7 \\
\hline Aphthous stomatitis & - & 1 & - & 1 & 2 & 4 \\
\hline Gingivitis/periodontitis & 1 & 7 & 2 & 6 & 16 & 28 \\
\hline Pyogenic granuloma & - & 1 & - & - & 1 & 2 \\
\hline Herpes virus & 1 & - & - & - & 1 & 2 \\
\hline Hyperpigmentation & - & - & 1 & 3 & 4 & 7 \\
\hline Traumatic hyperkeratosis & - & 2 & - & - & 2 & 4 \\
\hline Leukoplakia & - & 3 & 1 & 1 & 5 & 9 \\
\hline Lymphadenopathy & 1 & 5 & 2 & 2 & 10 & 18 \\
\hline TOTAL & 3 & 24 & 9 & 21 & 57 & 100 \\
\hline
\end{tabular}

\section{DISCUSSION}

In the present population of 79 HIV-infected patients, $47 \%(n=37)$ presented some type of oral lesion. Overall, 57 lesions were found, most patients (57\%) exhibiting only 1 lesion, followed by patients with 2 (35\%) or more lesions (8\%). One patient presented 4 lesions simultaneously, which included erythematous candidiasis, periodontitits, lymphadenopathy and pyogenic granuloma.

The high frequency of oral lesions in HIV-positive patients has been reported by Marcenes, et al. ${ }^{15}$ (1998), who examined 51 patients and observed oral lesions in $76.5 \%$ of cases. However, in a recent study conducted by Pinheiro, et al. ${ }^{24}$ (2004), only 33.5\% of HIV-positive patients exhibited oral lesions, with a low frequency of such lesions. The authors further related these oral manifestations with age, gender, transmission mode and type of therapy, and found no statistically significant differences among the results.

In the present survey, there was an equal number of occurrences of oral candidiasis and gingivitis/periodontitis, which were the most commonly found lesions, affecting 16 patients each. Both candidiasis and periodontal disease represented $28 \%$ of all lesions observed, adding up to more than half of the lesions (56\%). According to Gaitan-Cepeda, et al. ${ }^{7}$ (2005) and Perezous, et al. ${ }^{23}$ (2005), oral candidiasis is frequently the initial manifestation of symptomatic infection by the HIV, being observed in most patients. Oral candidiasis as the most common manifestation of AIDS was described by Ramos-Villegas, et al. ${ }^{25}$ (1992).

The prevalence of oral candidiasis ranges from 56 to $81 \%$ in Asia $^{1,20,26}$, from 0 to $94 \%$ in Africa ${ }^{9}$ and 5 to $92 \%$ in the United States ${ }^{11}$.

Three clinical manifestations of candidiasis were found in the present study. The most common was represented by erythematous candidiasis, also found by Perezous, et al. ${ }^{23}$ (2005). In the present study, it accounted for $12.5 \%$ of lesions, followed by pseudomembranous candidiasis and cheilitis (8.5\% and 7\%, respectively). On the other hand, Bendick, et al. ${ }^{2}$ (2002) reported that the most common lesion type was pseudomembranous candidiasis with 52.5\%, followed by erythematous candidiasis (22.8\%). There were no cases of hyperplastic candidiasis, as reported elsewhere $^{22,30}$. The third highest occurrence was persistent lymphadenopathy, which affected 10 cases (18\%).

The appearance of leukoplakia in the present study represented the 4th most frequent lesion, being found in $9 \%$ of the lesions (5 cases). It is worth mentioning that all of these patients made use of alcohol or smoking. However, some authors classified hairy leukoplakia as being the most frequent lesion in their studies ${ }^{15,21,22}$. This lesion is clinically manifested as white striae on the lateral tongue edges or other regions of the oral mucosa. Its characteristic location is related to the presence of specific receptors for the EpsteinBarr virus in parakeratinized areas of the oral mucosa, such as the lateral tongue edges ${ }^{24}$.

As reported by Tsang, et al. ${ }^{30}$ (1999), an important aspect of this study was the absence of cases of Kaposi's sarcoma, the malignant neoplasia most frequently associated with HIV contamination. However, Anil and Challacombe ${ }^{1}$ (1997) revealed a high incidence (50\%) of Kaposi's sarcoma in the studied population. This neoplasia, as well as hairy leukoplakia, has also been considered as being nearly pathognomonic of HIV infection ${ }^{10,14}$. According to epidemiological studies, the prevalence of this disease is 0 to $12 \%$ in Africa $^{17}$ and 0 to $38 \%$ in the USA and Europe ${ }^{16,28}$.

Melanin hyperpigmentation (7\%), ulcerative stomatitis (4\%), frictional keratosis (4\%), herpes simplex (2\%) and pyogenic granuloma (2\%) completed the sample of lesions.

Concerning the counting of CD4+ cells $/ \mathrm{mm}^{3}$ of blood, only $5 \%$ of patients without lesions presented more than 500 cells $/ \mathrm{mm}^{3}$ of blood. Most patients presented 500 to 200 cells $/ \mathrm{mm}^{3}$, adding up to $38 \%$ of cases, and $16 \%$ of patients exhibited counting of CD4+ cells lower than 200 cells $/ \mathrm{mm}^{3}$, which corresponded to the appearance of most severe 
manifestations associated to the HIV, including malignant neoplasia ${ }^{8,22}$.

When observing the risk behavior of patients with lesions, it was noticed that $49 \%$ of cases comprised heterosexual individuals (22\% males and 27\% females). Homosexuality was reported by only eleven male individual and represented $30 \%$ of patients. Injectable drug users included only males and represented $5 \%$ of the sample, whereas blood transfusion was reported only by females, adding up to $3 \%$ of all cases. In $2 \%$ patients, the virus had been transmitted from mother to child.

The highest incidence of lesions was observed for the admixture race, affecting $65 \%$ of patients in this group. The highest absolute number of lesions was also observed for the admixture race, adding up to 30 lesions (52\%), and 22 lesions were found among blacks, representing only $9 \%$ of all lesions. The most noticeable association between lesion and race was represented by the cases of periodontal disease, in which $62.5 \%$ of cases occurred in white individuals.

Concerning the presence of aggravating factors, denture wearing was uniformly distributed between candidiasis lesions and cases of periodontal disease (33.3\% each), without observation in asymptomatic patients. Unanimity was also found for the lesions diagnosed as hairy leukoplakia, and it should be highlighted that all patients with this type of lesion made use of alcohol and/or smoking.

\section{CONCLUSION}

The following conclusions may be drawn: 1. Patients with a lower CD4+ cell count presented a higher prevalence of lesions; 2. The larger number of HIV-positive heterosexual patients than homosexual individuals shows that HIV infection should not be associated only with homosexuals and injectable drug users; 3. Candidiasis and periodontal disease were the most common oral manifestations of HIV infection and the erythematous form was the most frequent among the clinical manifestations of candidiasis; 4. It was observed a very close relationship between alcohol and/or smoking use and the development of hairy leukoplakia in HIV-positive patients; 5 . The lowest prevalence of oral manifestations associated with HIV infection was observed among white patients (8.8\%).

\section{REFERENCES}

1- Anil S, Challacombe SJ. Oral lesions of HIV and AIDS in Asia: an overview. Oral Dis. 1997;3(Suppl 1):36-40.

2- Bendick C, Scheifele C, Reichart PA. Oral manifestations in 101 cambodians with HIV and AIDS. J Oral Pathol Med. 2002;31(1):1-4.

3- Carey VJ, Pahwa S, Weinberg A. Reliability of CD4 quantitation in human immunodeficiency virus-positive children: implications for definition of immunologic response to highly active anti retroviral therapy. Clin Diagn Lab Immunol. 2005;12(5):640-3.
4- Centers for Disease Control (CDC). Persistent, generalized lynphadenopathy among homosexual males. MMWR Morb Mortal Wkl Rep. 1982;31(19):249-51.

5- Chattopadhyay A, Caplan DJ, Slade GD, Shugars DC, Tien HC, Patton LL. Risk indicators for oral candidiasis and oral hair leukoplakia in HIVinfected adults. Community Dent Oral Epidemiol. 2005;33(1):35-44.

6- Faria PR, Vargas PA, Saldiva PH, Bohm GM, Mauad T, Almeida OP. Tongue disease in advanced AIDS. Oral Dis. 2005;11(2):72-80.

7- Gailan-Cepeda LA, Martinez-Gonzalez M, Ceballos-Salobrena A. Oral candidosis as a clinical marker of immune failure in patients with HIV/ AIDS on HAART. AIDS Patient Care STDS. 2005;19(2):70-7.

8- Hogg RS, Yip B, Chan KJ, Wood E, Craib KJ, O’Shaughnessy MV, et al. Rates of disease progression by baseline CD4 cell count and viral load after initiating triple-drug therapy. JAMA. 2001;286(20):2568-77.

9- Itula PFB, Mackenzie SBP, Lewis K, Mortimer PP. Orofacial manifestations and seroprevalence of HIV infection in Namibian dental patients. Oral Dis. 1997;3(Suppl 1):S51-3.

10- Kua HW, Merchant W, Waugh MA. Oral Kaposi's Sarcoma in a nonHIV homosexual white male. Int J Std AIDS. 2004;15(11):775-7.

11- Lamster IB, Begg MD, Mitchell-Lewis D, Fine JB, Grbic JT, Todak GG, et al. Oral manifestations of HIV infection in homosexual men and intravenous drug users. Study design and relationship of epidemiologic, clinical and immunologic parameters to oral lesions. Oral Surg Oral Med Oral Pathol. 1994;78(2):163-74.

12- Lilly EA, Cameron JE, Shetty KV, Leigh JE, Hager S, McNulty KM, et al. Lack of evidence for local immune activity in oral hair leukoplakia and oral wart lesions. Oral Microbiol Immunol. 2005;20(3):154-62.

13- Lugo RI, Fornatora ML, Reich RF, Freedman PD. Linear gingival erythema in an HIV-seropositive man. AIDS Read. 1999;9(2):97-9.

14- Lynen L, Zolfo M, Huyst V, Louis F, Barnardt P, Van de Velde A, et al. Management of Kaposi's sarcoma in source-limited settings in the era of HAART. AIDS Rev. 2005;7(1):13-21.

15- Marcenes W, Pankhurst CL, Lewis DA. Oral health behaviour and the prevalence of oral manifestations of HIV infection in a group of HIV positive adults. Int Dent J. 1998;48(6):557-62.

16- Margiotta V, Campisi G, Mancuso S, Accurso V, Abbadessa V. HIV infection: oral lesions, CD4+ cell count and viral load in an Italian study population. J Oral Pathol Med. 1999;28:173-7.

17- Matee MI, Scheutz F, Moshy J. Occurrence of oral lesions in relation to clinical and immunological status among HIV-infected adult tanzanians. Oral Dis. 2000;6(2):106-11.

18- Mbopi-Keou FX, Mbu RE, Gonsu Kamga H, Kalla GC, Monny Lobe $\mathrm{M}$, Teo CG, et al. Interactions between human immunodeficiency virus and herpes viruses within the oral mucosa. Clin Microbiol Infect. 2005;11(2):83-5.

19- Neville BW, Damm DD, Allen CM, Bouquot JE. Oral \& maxillofacial pathology. Philladelphia: Saunders Company; 1995.

20- Nittayananta W, Chungpanich S. Oral lesions in a group of Thai people with AIDS. Oral Dis. 1997;3(Suppl 1):S41-5.

21- Patton LL. Immunologic and viral markers of HIV-1 disease progression: implications for dentistry. J Am Dent Assoc. 1999;130(9):1313-22.

22- Patton LL, McKaig RG, Strauss RP, Eron JJ Jr. Oral manifestations of HIV in a southeast USA population. Oral Dis. 1998;4(3):164-9. 
23- Perezous LF, Flaitz CM, Goldschmidt ME, Engelmeier RL. Colonization of candida species in denture wearers with emphasis on HIV infection: a literature review. J Prosthet Dent. 2005;93(3):288-93.

24- Pinheiro A, Marcenes W, Zakrzewska JM, Robinson PG. Dental and Oral lesions in HIV infected patients: a study in Brazil. Int Dent J. 2004(3);54:131-7.

25- Ramos-Villegas A, Martinez-Aguilar G, Cuaran-Ruiduaz V, SantosPreciado JI, Valencia-Mayoral P. Oral Manifestations in HIV-positive children. Bol Med Hosp Infant Mexico. 1992;49(9):592-9.

26- Ranganathan K, Reddy BV, Kumarasamy N, Solomon S, Viswanathan $\mathrm{R}$, Johnson NW. Oral lesions and conditions associated with human immunodeficiency virus infection in 300 south Indian patients. Oral Dis. 2000;6(3):152-7.

27- Reichart PA. Oral manifestations in HIV infection: fungal and bacterial infections, Kaposi’s Sarcoma. Med Microbiol Immunol. 2003;192(3):165-

28- Schuman P, Ohmit SE, Sobel JD, Mayer KH, Greene V, Rompalo A, et al. Oral lesions among women living with or at risk for HIV infection. Am J Med. 1998;104(6):559-64.

29- Shangase L, Feller L, Blignaut E. Necrotising ulcerative gingivitis/ periodontitis as indicators of HIV-infection. SADJ. 2004;59:105-8.

30- Tsang PCS, Samaranayake LP. Oral manifestations of HIV infection in a group of predominantely ethnic Chinese. J Oral Pathol Med. 1999;28(3):122-7. 